\title{
Hubungan Antara Fleksibilitas Otot Hamstring dengan Nyeri Punggung Bawah pada Wanita Usia 18-22 Tahun
}

\author{
${ }^{1}$ Puspita Asri Pradipta, ${ }^{2}$ Adnan Faris Naufal, ${ }^{3}$ Istimrorul Najibatil Fikriyah, ${ }^{4}$ Nadiah Ulfah \\ ${ }^{1}$ Program Studi, Fakultas Ilmu Kesehatan, Universitas Muhammadiyah Surakarta \\ Jl. A. Yani Tromol Pos I Pabelan Kartasura Telp. (0271) 717417 Fax. (0271) 715448 Surakarta 57162 \\ Email : pusribbon17@gmail.com \\ Tanggal Submisi: 30 Januari 2020; Tanggal Penerimaan: 03 Desember 2021
}

\begin{abstract}
ABSTRAK
Nyeri Punggung Bawah (NPB) didefinisikan sebagai "nyeri, ketegangan otot atau kekakuan yang terlokalisasi di bawah batas kosta dan di atas lipatan gluteal inferior, dengan atau tanpa nyeri kaki rujukan". Kurangnya fleksibilitas hamstring dikaitkan dengan kerentanan terhadap cedera muskuloskeletal seperti nyeri punggung bawah. Tujuan penelitian ini yaitu untuk mengetahui hubungan antara fleksibilitas otot hamstring dengan nyeri punggung bawah pada wanita usia 18-22 tahun. Penelitian ini menggunakan desain penelitian cross-sectional dengan subyek penelitian adalah mahasiswa perempuan fisioterapi Universitas Muhammadiyah Surakarta yang berusia 18-22 tahun sebanyak 109 orang. Pengukuran fleksibilitas otot hamstring menggunakan tes sit and reach dan kuesioner Oswestry Disability Index (ODI) digunakan untuk mengukur kemampuan fungsional NPB. Data yang dikumpulkan dianalisa menggunakan uji korelasi Spearman Rank. Hasil penelitian didapatkan nilai $\mathrm{p}=0.000$, nilai $\mathrm{r}=0.644$, dan arah korelasi negatif sehingga penelitian ini menunjukkan adanya hubungan signifikan yang kuat dan tidak searah antara fleksibilitas otot hamstring dengan nyeri punggung bawah pada wanita usia 18-22 tahun.
\end{abstract}

Kata kunci: Fleksibilitas otot hamstring, nyeri punggung bawah, tes sit and reach, Oswestry Disability Index

\begin{abstract}
Low Back Pain (LBP) is defined as "pain, muscle tension or stiffness that is localized below the costal margin and above the inferior gluteal fold, with or without referral leg pain". Lack of hamstring flexibility is associated with susceptibility to musculoskeletal injuries such as low back pain. The purpose of this study was to determine the relationship between hamstring muscle flexibility and low back pain in women aged 18-22 years. This study used a cross-sectional study design with 109 subjects as physiotherapy female students of Muhammadiyah Surakarta University, aged 18-22 years. Measurement of hamstring muscle flexibility using sit and reach tests and the Oswestry Disability Index (ODI) questionnaire were used to measure the functional ability of LBP. The data collected was analyzed using the Spearman Rank correlation test. The results obtained $\mathrm{p}$ value $=0.000, \mathrm{r}$ value $=0.644$, and the direction of correlation was negative so that this study showed a significant relationship with negative direction between the hamstring muscles flexibility and low back pain in women aged 18-22 years.
\end{abstract}

Keywords: hamstring muscle flexibility, low back pain, sit and reach test, Oswestry Disability Index.

ISSN 2722-9610

E - ISSN 2722-9629 


\section{Pendahuluan}

Salah satu kebiasaan paling umum di kalangan mahasiswa adalah duduk dalam waktu lama. Duduk lama telah diidentifikasi sebagai salah satu faktor yang menyebabkan Nyeri Punggung Bawah (NPB) atau Low Back Pain (LBP) di kalangan mahasiswa. Oleh karena itu, sejumlah besar mahasiswa dapat mengalami NPB karena menghabiskan terlalu banyak waktu dalam posisi duduk untuk membaca atau bekerja di komputer (Anggiat, Hon, \& Baait, 2018). Studi yang dilakukan Anggiat et al. (2018) menunjukkan prevalensi nyeri punggung bawah sebesar $74,6 \%$, dengan usia rata-rata $20,39 \pm 1,77$ tahun. Mayoritas peserta adalah perempuan $(85,2 \%)$ dan siswa tahun ketiga $(40,2 \%)$ (Anggiat et al., 2018). Dalam studi pendahuluan yang dilakukan kepada mahasiswa perempuan usia 1822 tahun prodi fisioterapi di Universitas Muhammadiyah Surakarta pada bulan Oktober 2019, tercatat ada 68 orang mahasiswa perempuan yang belakangan ini sedang merasakan nyeri punggung bawah.

Kurangnya fleksibilitas hamstring dikaitkan dengan kerentanan terhadap cedera muskuloskeletal seperti nyeri punggung bawah. Karena asal atau origo otot hamstring yang terletak di tuberositas ischiadicus pelvis, fleksibilitas hamstring dapat mempengaruhi rotasi pelvis (Naufal, 2019). Rotasi pelvis yang terbatas dapat menyebabkan penurunan gerakan lumbal dan trauma mikro berulang yang mungkin merupakan faktor dalam pengembangan nyeri punggung bawah (Hasarangi \& Jayawardana, 2018). Gerakan pelvic tilt ke arah anterior maupun posterior mempengaruhi tulang belakang. Pada saat pelvic tilt anterior, terjadi peningkatan lordosis pada tulang belakang lumbal. Tindakan ini cenderung menggeser nukleus pulposus ke depan dan menurunkan diameter foramina intervertebralis. Sebaliknya, pelvic tilt posterior membuat tulang belakang fleksi dan mengurangi lordosis pada lumbal. Tindakan ini cenderung menggeser nukleus pulposus ke posterior dan meningkatkan diameter foramina intervertebralis. Rentang gerak untuk pelvic tilt ke anterior adalah sekitar $30^{\circ}$ sedangkan untuk pelvic tilt posterior adalah $15^{\circ}$. (Mansfield \& Neumann, 2019). Tes Sit and Reach dilakukan untuk menguji fleksibilitas hamstring serta rentang gerak panggul dan tulang belakang selama membungkuk ke depan. Intraclass Correlation Coefficient (ICC) untuk tes Sit and Reach adalah 0.92 (Frey et al., 2019).

$$
\text { Nyeri Punggung Bawah (NPB) }
$$

didefinisikan sebagai "nyeri, ketegangan otot atau kekakuan yang terlokalisasi di bawah batas kosta dan di atas lipatan gluteal inferior, dengan atau tanpa nyeri kaki rujukan" (Airaksinen et al., 2006; Tulder et al., 2001; Chou, 2010). Berdasarkan penelitian yang dilakukan oleh Lionel (2014), faktor risiko yang signifikan didapatkan pada postur yang buruk, kurangnya latihan fisik, adanya NPB terkait dengan gen, tingkat edukasi yang rendah, nutrisi yang buruk. Aktivitas fisik seperti mengangkat beban yang berat seringkali juga menyebabkan NPB. Latar belakang sosial-ekonomi yang rendah, kebiasaan merokok, mengonsumsi alkohol, kehamilan, obesitas, dan berat badan yang terlalu rendah ditemukan menjadi faktor risiko yang signifikan dalam beberapa penelitian (Lionel, 2014). Oswestry Disability Index (ODI) menilai gejala dan keparahan nyeri punggung bawah dalam hal disabilitas dan sejauh mana sakit punggung atau tungkai berdampak pada aktivitas fungsional. ODI merupakan kuesioner yang terdiri dari 8 sampai 10 item. Setiap item terdiri dari enam pernyataan yang berkorelasi dengan skor 0 hingga 5 , dengan pasien memilih pernyataan yang sesuai dengan kemampuannya. Pernyataan yang berkorelasi dengan skor 0 menunjukkan disabilitas yang paling rendah, dan pernyataan yang berkorelasi dengan 5 mewakili disabilitas terbesar. Intraclass Correlation Coefficient (ICC) untuk ODI adalah 0.97 (Miekisiak et al., 2013). 


\section{Metode Penelitian}

Penelitian ini merupakan jenis penelitian observasional yang menggunakan desain penelitian cross-sectional. Penelitian dilakukan pada 135 orang mahasiswa perempuan fisioterapi Universitas Muhammadiyah Surakarta yang berusia 18-22 tahun pada minggu ke dua Januari 2020 dengan metode pengambilan sampel menggunakan simple random sampling. Sebanyak 109 orang memenuhi kriteria inklusi yaitu: (a) mahasiswa perempuan fisioterapi Universitas Muhammadiyah Surakarta, (b) Usia 18-22 tahun. Sebanyak 26 orang memenuhi kriteria eksklusi yaitu: (a) cedera lutut, (b) deformitas lutut dan fraktur di sekitar sendi lutut dengan keterbatasan rentang gerakan, (c) nyeri menjalar yang berasal dari punggung atau sendi lutut, (d) adanya kelainan bentuk tulang belakang (skoliosis dll.) maupun pada tungkai bawah, (e) memiliki perbedaan panjang tungkai, (f) responden yang telah menjalani operasi di punggung (g) responden sedang dalam masa menstruasi.

Posedur penelitian yaitu diawali dengan penjelasan tentang tujuan, manfaat, prosedur, dampak, dan kompensasi jika mengikuti prosedur penelitian kepada responden. Responden mengisi lembar persetujuan responden (informed consent). Responden mengisi kuesioner untuk menentukan kriteria inklusi dan eksklusi. Responden mengisi kuesioner Oswestry Disability Index. Pengukuran fleksibilitas hamstring menggunakan sit and reach box dengan cara: (a) responden duduk dengan tungkai lurus di lantai tanpa menggunakan alas kaki, (b) jari-jari kaki hingga tumit responden bersentuhan dengan sit and reach box (c) responden membungkukkan badan ke depan serta menjulurkan kedua lengan ke depan sejauh mungkin di atas garis yang berukuran sentimeter (d) enumerator pertama memfiksasi lutut responden untuk memastikan lutut benar-benar lurus (e) enumerator kedua mencatat jarak terjauh yang mampu dicapai oleh responden.

\section{Hasil}

Pada penelitian ini ada beberapa karakteristik yang diperoleh berdasarkan hasil pengukuran yang dilakukan pada 109 responden. Tabel 1 merupakan data yang berisi deskriptif karakteristik responden. Selain itu terdapat data interpretasi hasil persentase nilai ODI pada Tabel 2.

Tabel 1. Deskriptif Karakteristik Responden

\begin{tabular}{ccccc}
\hline Karakteristik & Min & Max & Mean & SD \\
\hline Usia & 18 & 22 & 19.63 & 1.26 \\
\hline $\begin{array}{c}\text { Skor sit and } \\
\text { reach test }\end{array}$ & 10 & 44 & 25.20 & 8.61 \\
\hline Persentase ODI & 0.00 & 17.78 & 3.06 & 3.65 \\
\hline
\end{tabular}

Tabel 2. Gambaran Karakteristik Responden Berdasarkan Interpretasi Oswestry Disability Index (ODI)

\begin{tabular}{clcc}
\hline $\begin{array}{c}\text { Persentase } \\
\text { ODI }\end{array}$ & Kategori & N & Persentase \\
\hline $0 \%-20 \%$ & $\begin{array}{l}\text { Disabilitas } \\
\text { minimal }\end{array}$ & 102 & $100 \%$ \\
\hline $21 \%-40 \%$ & $\begin{array}{l}\text { Disabilitas } \\
\text { sedang }\end{array}$ & 0 & $0 \%$ \\
\hline $41 \%-60 \%$ & $\begin{array}{l}\text { Disabilitas } \\
\text { berat }\end{array}$ & 0 & $0 \%$ \\
\hline $61 \%-80 \%$ & Lumpuh & 0 & $0 \%$ \\
\hline $81 \%-100 \%$ & & 0 & $0 \%$ \\
\hline
\end{tabular}




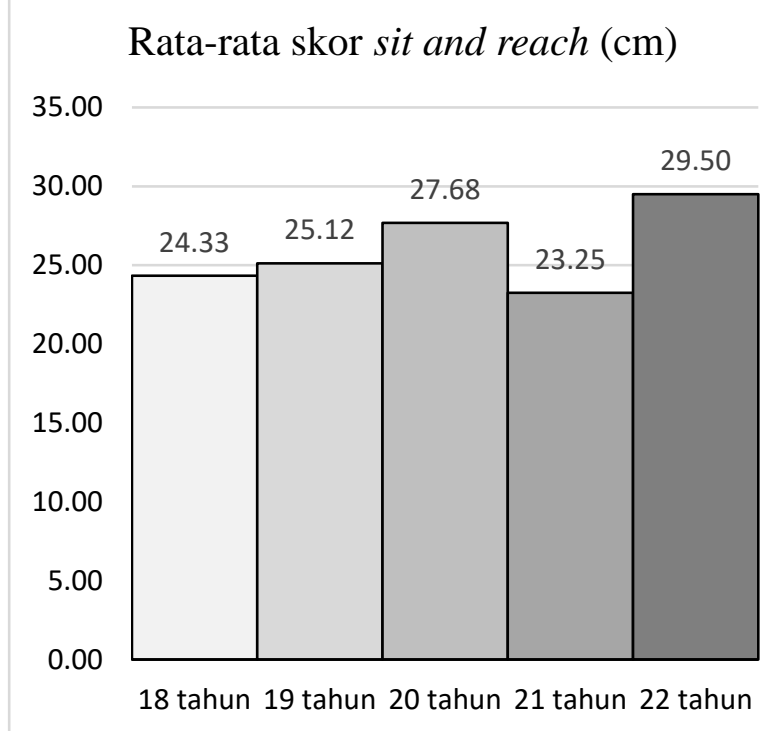

Gambar 1. Diagram batang rata-rata skor sit and reach berdasarkan usia

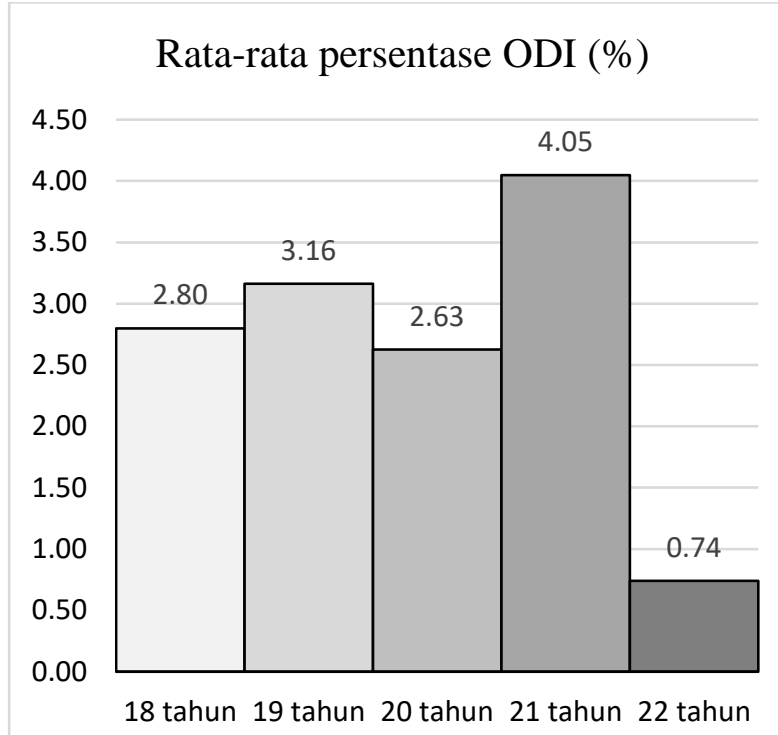

Gambar 2. Diagram batang rata-rata persentase ODI berdasarkan usia

Dari gambar 1 di atas dapat dilihat bahwa usia 21 tahun memiliki rata-rata skor sit and reach paling rendah yaitu $23.25 \mathrm{~cm}$ dan usia 22 tahun memiliki rata-rata skor sit and reach paling tinggi yaitu $29.50 \mathrm{~cm}$. Sedangkan pada gambar 2 menunjukkan rata-rata persentase ODI paling tinggi adalah usia 21 tahun yaitu $4.05 \%$ dan paling rendah usia 22 tahun yaitu $0.74 \%$.
Analisis data dilakukan pada skor sit and reach untuk mengukur fleksiblitas hamstring dan persentase ODI untuk mengukur kemampuan fungsional penderita nyeri punggung bawah. Pengelolaan data dilakukan dengan menggunakan IBM SPSS Statistics. Peneliti melakukan uji normalitas data dengan menggunakan uji Kolmogorov-Smirnov.

Data berdistribusi normal jika $\mathrm{p}>0.05$ dan dapat dilihat dari tabel 3 untuk skor sit and reach dengan nilai signifikan 0.005 dan persentase ODI dengan nilai 0.000. Dapat dilihat bahwa kedua data tersebut memiliki nilai kurang dari 0.05 sehingga data tersebut berdistribusi tidak normal. Oleh karena data berdistribusi tidak normal, maka peneliti menggunakan uji korelasi Spearman Rank.

Tabel 3 Uji Normalitas Data antara Skor Sit and Reach dan Persentase ODI

\begin{tabular}{ccc}
\hline & Nilai p & Keterangan \\
\hline $\begin{array}{c}\text { Skor sit and } \\
\text { reach }\end{array}$ & 0.001 & $\begin{array}{l}\text { Berdistribusi } \\
\text { tidak normal }\end{array}$ \\
\hline $\begin{array}{c}\text { Persentase } \\
\text { ODI }\end{array}$ & 0.000 & $\begin{array}{l}\text { Berdistribusi } \\
\text { tidak normal }\end{array}$ \\
\hline
\end{tabular}

Tabel 4 Uji Korelasi antara Skor Sit and Reach dengan Persentasi ODI menggunakan Spearman Rank

\begin{tabular}{ccc}
\hline Uji Korelasi & Nilai & Keterangan \\
\hline Nilai $\mathrm{p}$ & 0.000 & $\begin{array}{c}\mathrm{p}<0.05 \\
\text { Signifikan }\end{array}$ \\
\hline Nilai $\mathrm{r}$ & 0.644 & Kuat \\
\hline Arah Korelasi & $(-)$ & Negatif \\
\hline
\end{tabular}

Tabel 4 merupakan hasil uji korelasi antara skor sit and reach dengan persentase ODI menggunakan uji korelasi Spearman Rank. Berdasarkan tabel tersebut didapatkan bahwa skor sit and reach memiliki hubungan atau berkorelasi dengan persentase ODI karena memiliki nilai signifikansi 0.000 yang berarti memiliki nilai signifikansi $\mathrm{p}<0.05$. Dari tabel 
tersebut diketahui skor sit and reach dan persentase ODI memiliki nilai $\mathrm{r}$ sebesar 0.644 atau berkorelasi kuat dan memiliki arah negatif. Berdasarkan data yang telah diolah peneliti, didapatkan hasil yaitu adanya hubungan kuat antara skor sit and reach yang merupakan hasil dari pengukuran fleksibilitas otot hamstring dengan persentase ODI yang merupakan hasil dari pengukuran kemampuan fungsional untuk penderita nyeri punggung bawah. Keduanya dikatakan memiliki hubungan karena nilai signifikansi yang didapatkan yaitu 0.000 yang berarti H0 ditolak karena $\mathrm{p}<0.005$. Selain itu hubungan keduanya bernilai kuat karena mempunyai nilai $r$ atau koefisien korelasi sebesar 0.644. Koefisien korelasi dikatakan memiliki hubungan kuat apabila memiliki nilai antara 0.510.75. Arah hubungan negatif artinya hubungan

tidak searah yaitu apabila skor sit and reach meningkat, maka persentase ODI menurun.

\section{Pembahasan}

Fleksibilitas otot hamstring yang kurang baik atau biasa disebut hamstring tightness dapat membuat pelvic tilt ke arah posterior sehingga tulang belakang lumbal menjadi hypolordosis. Hal ini dapat meningkatkan tekanan pada struktur anterior tulang belakang termasuk diskus intervertebralis. Tekanan yang berulang dan secara terus menerus akan menybabkan degenerasi diskus sehingga menimbulkan keluhan nyeri punggung bawah. Hal ini sesuai dengan penelitian yang dilakukan oleh Hasarangi dan Jayawardana pada tahun 2018 yang menyimpulkan bahwa fleksibilitas hamstring pada pasien dengan nyeri punggung bawah kronik secara signifikan lebih rendah $(\mathrm{p}<0.05)$ dibandingkan dengan orang sehat. Selain penelitian tersebut, ada pula penelitian yang dilakukan oleh Francis et. al pada tahun 2016 yang menyimpulkan bahwa peserta dengan nyeri punggung bawah memiliki panjang otot hamstring yang secara signifikan lebih pendek
( $\mathrm{p}=0.01)$ dibandingkan peserta tanpa keluhan nyeri punggung bawah.

Penelitian lain yang dilakukan oleh Mistry et. al tahun 2014 menunjukkan bahwa ada perbedaan yang signifikan dari hamstring tightness antara pasien yang mengalami nyeri punggung bawah dan orang sehat (Mistry et. al, 2014). Demikian pula, dilaporkan bahwa fleksibilitas hamstring sangat berkorelasi dengan rotasi pelvis dan luas gerak sendi untuk gerakan fleksi trunk, hal ini dapat mempengaruhi daerah lumbal dan dalam penelitian ini terdapat korelasi kuat antara fleksibilitas hamstring dan nyeri punggung bawah (Bellew et.al, 2010).

\section{Kesimpulan dan Saran}

Kesimpulan dari penelitian ini yaitu adanya hubungan signifikan yang kuat dan tidak searah antara fleksibilitas otot hamstring dengan nyeri punggung bawah pada wanita usia 18-22 tahun.

Penelitian selanjutnya disarankan untuk melakukan penelitian dengan rentang usia responden tidak hanya 18-22 tahun agar hasil pengukuran yang didapatkan lebih bervariasi dan penelitian pada responden laki-laki juga perlu diteliti sebagai perbandingan. Responden disarankan untuk (a) melakukan latihan fleksibilitas otot hamstring seperti stretching dan mobilisasi pelvis (anterior-postrior-lateral pelvic tilt), (b) edukasi posisi yang ergonomis ketika melakukan aktivitas sehari-hari seperti mengangkat barang, duduk, berdiri, tidur, (c) home exercise program untuk mengatasi nyeri punggung bawah.

\section{Daftar Pustaka}

Airaksinen, O., Brox, J. I., Cedraschi, C., Hildebrandt, J., Klaber-Moffett, J., Kovacs, F., Ursin, H. (2006). Chapter 4 European guidelines for the management of chronic nonspecific low back pain. European Spine Journal, 15, s192-s300.

Anggiat, L., Hon, W. H. C., \& Baait, S. N. (2018). 
The Incidence of Low Back Pain Among University Students. Pro-Life, 5(3), 677687.

Bellew, S., Ford, H., \& Shere, E. (2010). The relationship between hamstring flexibility and pelvic rotation around the hip during forward bending. The Plymouth Student Journal of Health \& Social Work, 19-29.

Chou, R. (2010). Low back pain (chronic). BMJ Clinical Evidence, 2010.

Frey, M., Poynter, A., Younge, K., \& De Carvalho, D. (2019). The relationship between lumbopelvic flexibility and sitting posture in adult women. Journal of Biomechanics, 84, 204-210.

Hasarangi, L. B. S., \& Jayawardana, D. (2018). Comparison of Hamstring Flexibility between Patients with Chronic Lower Back Pain and the Healthy Individuals at the National Hospital of Sri Lanka. 5(2), 44104413.

https://doi.org/10.26717/BJSTR.2018.05.0 01171

Lionel, K. A. (2014). Risk factors forchronic low back pain. J Community Med Health Educ, 4(271), 711-2161.

Mansfield, P. J., \& Neumann, D. A. (2019). Chapter 8 - Structure and Function of the
Vertebral Column (P. J. Mansfield \& D. A. B. T.-E. of K. for the P. T. A. (Third E. Neumann, eds.). https://doi.org/https://doi.org/10.1016/B978 -0-323-54498-6.00008-4

Miekisiak, G., Kollataj, M., Dobrogowski, J., Kloc, W., Libionka, W., Banach, M., Nowakowski, A. (2013). Validation and cross-cultural adaptation of the Polish version of the Oswestry Disability Index. Spine, 38(4), E237-E243.

Mistry, G. S., Vyas, N. J., \& Sheth, M. S. (2014). Comparison of hamstrings flexibility in subjects with chronic low back pain versus normal individuals. J Clin Exp Res, 2(1), $85-88$.

Naufal, A. F., 2019. Mengenal Dan Memahami Fisioterapi Anak. Cetakan Pertama ed. Surakarta: Penerbit Muhammadiyah University Press.

Tulder, M. W., Becker, A., Bekkering, T., Breen, A., Real, M. T., \& Hutchinson, A. (2001). Working Group on Guidelines for the Management of Acute Low Back Pain in Primary Care. European Guidelines for the Management of Acute Non Specific Low Back Pain in Primary Care. 